\title{
Universiteit
}

Leiden

The Netherlands

\section{Protein-induced bonding perturbation of the rhodopsin chromophore detected by double-quantum solid-state NMR}

Carravetta, M.; Zhao, .X; Johannessen, O.G.; Lai, W.C.; Verhoeven, M.A.; Bovee-Geurts, P.H.M.; ... ; Levitt, M.H.

\section{Citation}

Carravetta, M., Zhao, .X., Johannessen, O. G., Lai, W. C., Verhoeven, M. A., Bovee-Geurts, P. H. M., ... Levitt, M. H. (2004). Protein-induced bonding perturbation of the rhodopsin chromophore detected by double-quantum solid-state NMR. Journal Of The American Chemical Society, 126(12), 3948-3953. doi:10.1021/ja039390q

Version: $\quad$ Publisher's Version

License: $\quad$ Licensed under Article 25fa Copyright Act/Law (Amendment Taverne)

Downloaded from: https://hdl.handle.net/1887/3239399

Note: To cite this publication please use the final published version (if applicable). 


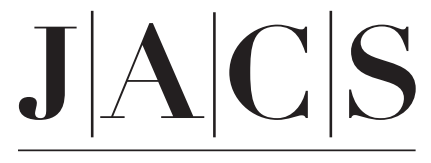

A R T I C L E S

Published on Web 03/06/2004

\title{
Protein-Induced Bonding Perturbation of the Rhodopsin Chromophore Detected by Double-Quantum Solid-State NMR
}

\author{
Marina Carravetta, ${ }^{\S},{ }^{\dagger}$ Xin Zhao,,${ }^{\S} \dagger$ Ole G. Johannessen, ${ }^{\dagger}$ Wai Cheu Lai, ${ }^{\dagger}$ \\ Michiel A. Verhoeven, ${ }^{\ddagger}$ Petra H. M. Bovee-Geurts," Peter J. E. Verdegem, ${ }^{\prime}$ \\ Suzanne Kiihne, ${ }^{\ddagger}$ Henrik Luthman, $\$$ Huub J. M. de Groot, ${ }^{\ddagger}$ Willem J. deGrip, $\neq, \| l$ \\ Johan Lugtenburg, ${ }^{\ddagger}$ and Malcolm H. Levitt ${ }^{\star}, \dagger$ \\ Contribution from the Physical Chemistry Division, Stockholm University, \\ S-106 91 Stockholm, Sweden, Chemistry Department, Southampton University, \\ S017 1BJ Southampton, U.K., Leiden Institute of Chemistry, Leiden University, NL-2300 RA \\ Leiden, The Netherlands, and Nijmegen Center for Molecular Life Sciences, University of \\ Nijmegen Medical School, NL-6500 HB Nijmegen, The Netherlands
}

Received November 3, 2003; E-mail: mhl@soton.ac.uk

\begin{abstract}
We have obtained carbon-carbon bond length data for the functional retinylidene chromophore of rhodopsin, with a spatial resolution of $3 \mathrm{pm}$. The very high resolution was obtained by performing doublequantum solid-state NMR on a set of noncrystalline isotopically labelled bovine rhodopsin samples. We detected localized perturbations of the carbon-carbon bond lengths of the retinylidene chromophore. The observations are consistent with a model in which the positive charge of the protonated Schiff base penetrates into the polyene chain and partially concentrates around the $\mathrm{C} 13$ position. This coincides with the proximity of a water molecule located between the glutamate-181 and serine-186 residues of the second extracellular loop, which is folded back into the transmembrane region. These measurements support the hypothesis that the polar residues of the second extracellular loop and the associated water molecule assist the rapid selective photoisomerization of the retinylidene chromophore by stabilizing a partial positive charge in the center of the polyene chain.
\end{abstract}

\section{Introduction}

Rhodopsin is a G-protein coupled receptor responsible for dim light vision in vertebrates. It has been the subject of numerous structural studies, ${ }^{1-3}$ including solid-state $\mathrm{NMR}^{4-8}$ and X-ray diffraction (XRD), ${ }^{9,10}$ with a resolution of $2.6 \AA$ in the latest refinement. ${ }^{10}$ The light-sensitive element of rhodopsin

§ Stockholm University.

† Southampton University.

$\doteqdot$ Leiden University.

"University of Nijmegen Medical School.

(1) Mathies, R. A.; Lugtenburg, J. The Primary Photoreaction of Rhodopsin; In Molecular Mechanisms in Visual Transduction; Stavenga, D. G., deGrip, W. J., and Pugh, E. N., Jr., Eds.; Elsevier Science: Amsterdam, The Netherlands, 2000; pp 55-90

(2) Menon, S. T.; Han, M.; Sakmar, T. P. Physiol. Rev. 2001, 81, 1659-1688

(3) Filipek, S.; Stenkamp, R. E.; Teller, D. C.; Palczewski, K. G. Annu. Rev. Physiol. 2003, 65, 851-879.

(4) Spooner, P. J. R.; Sharples, J. M.; Verhoeven, M. A.; Lugtenburg, J.; Glaubitz, C.; Watts, A. Biochemistry 2002, 41, 7549-7555.

(5) Feng, X.; Verdegem, P. J. E.; Lee, Y. K.; Sandström, D.; Edén, M.; BoveeGeurts, P. H. M.; deGrip, W. J.; Lugtenburg, J.; de Groot, H. J. M.; Levitt, M. H. J. Am. Chem. Soc. 1997, 119, 6853-6857.

(6) Feng, X.; Verdegem, P. J. E.; Eden, M.; Sandström, D.; Lee, Y. K.; BoveeGeurts, P. H. M.; deGrip, W. J.; Lugtenburg, J.; de Groot, H. J. M.; Levitt, M. H. J. Biomol. NMR 2000, 16, $1-8$.

(7) Verdegem, P. J. E.; Bovee-Geurts, P. H. M.; deGrip, W. J.; Lugtenburg, J.; de Groot, H. J. M. Biochemistry 1999, 38, pp 11316-11324.

(8) Verhoeven, M. A.; Creemers, A. F. L.; Bovee-Geurts, P. H. M.; deGrip, W. J.; Lugtenburg, J.; de Groot, H. J. M. Biochemistry 2001, 40, 32823288.

(9) Palczewski, K.; Kumasaka, T.; Hori, T.; Behnke, C. A.; Motoshima, H.; Fox, B. A.; Le Trong, I.; Teller, D. C.; Okada, T.; Stenkamp, R. E.; Yamamoto, M.; Miyano, M. Science 2000, 289, 739-745.

(10) Okada, T.; Fujiyoshi, Y.; Silow, M.; Navarro, J.; Landau, E. M.; Shichida, Y. Proc. Natl. Acad. Sci. U.S.A. 2002, 99, 5982-5987. is the retinylidene chromophore, which is attached to the lysine296 residue of the opsin protein by a protonated Schiff base (PSB) linkage. The $11-Z$ chromophore is isomerized to $11-E$ by absorption of a photon. This isomerization is both very efficient (67\% quantum yield ${ }^{11,12}$ ) and ultra-rapid (less than 200 $\mathrm{fs}^{13,14}$ ). The light-induced conformational change of the chromophore triggers a series of structural changes in the protein which eventually lead to activation of the cytoplasmic surface domain followed by binding and activation of the G-protein transducin. ${ }^{15}$

One remarkable feature of the rhodopsin crystal structure ${ }^{9,10}$ is the ingression of the extracellular loop II (EII) into the interior of the protein, so that the polar residues Glu-181 and Ser-186 approach the retinylidene chromophore closely. These two residues, together with two structural water molecules and the PSB counterion Glu-113, form a hydrogen-bonded polar strip which closely approaches the formally hydrophobic chromophore. Recent studies ${ }^{16,17}$ have identified a "counterion

(11) Dartnall, H. J. A.; In Photochemistry of Vision; Dartnall, H. J. A., Ed. Springer-Verlag: Berlin, 1972; pp 122-145.

(12) Kim, J. E.; Tauber, M. J.; Mathies, R. A. Biochemistry 2001, 40, 1377413778.

(13) Schoenlein, R. W.; Peteanu, L. A.; Mathies, R. A.; Shank, C. V. Science 1991, 254, 412-415.

(14) Peteanu, L. A.; Schoenlein, R. W.; Wang, Q.; Mathies, R. A.; Shank, C. V. Proc. Natl. Acad. Sci. U.S.A. 1993, 90, 11762-11766.

(15) Stryer, L. J. Biol. Chem. 1991, 266, 10711-10714. 
switch" in which a proton is transferred along this chain for the metarhodopsin-I state, as part of the activation mechanism during the final stages of the photocycle.

In this article, we present experimental evidence that the polar EII loop residues and the associated water molecules also play a strong role in the initial photoisomerization, which is extraordinarily fast and selective. For protonated retinylidene Schiff bases, the positive iminium charge is partially delocalized into the polyene chain, adjacent to the Schiff base. Doublequantum (DQ) ${ }^{13} \mathrm{C}$ solid-state NMR measurements, which are capable of spatial resolution of the order of picometers, provide convincing evidence of perturbations of the polyene double and single bonds in the vicinity of the isomerization site, suggesting the partial delocalization of the protein-bound PSB positive charge well into the chain. The location of the partial positive charge coincides with the close approach of the structural water molecule between the Glu-181 and Ser-186 residues of the EII loop. We postulate that the polar EII residues assist the photoisomerization by perturbing the conjugation in the $\mathrm{C} 11$ to $\mathrm{C} 13$ region of the chromophore.

This is the first time that structural data with a resolution of a few picometers have been reported for a functional biomolecule and illustrates the useful complementarity of X-ray crystallography and solid-state NMR.

\section{Methods}

2.1. Sample Preparation. We prepared five samples of rhodopsin, each labeled with a pair of neighboring ${ }^{13} \mathrm{C}$ nuclei, at different positions in the retinylidene chain, while maintaining in the natural membrane $\left[10,11-{ }^{13} \mathrm{C}_{2}-\right.$ retinylidene $],\left[11,12-{ }^{13} \mathrm{C}_{2}-\right.$ retinylidene $],\left[12,13-{ }^{13} \mathrm{C}_{2}-\right.$ retinylidene], $\left[13,14-{ }^{13} \mathrm{C}_{2}\right.$-retinylidene $]$, and $\left[14,15-{ }^{13} \mathrm{C}_{2}-\right.$ retinylidene $]$ rhodopsin. The labeled all-E-retinals were synthesized by modular organic synthesis. ${ }^{18}$ The bovine rhodopsin samples were prepared by incorporating the labeled 11-Z-retinals in the apoprotein opsin, isolated from fresh cattle eyes, and subsequent removal of the excess retinal according to published procedures. ${ }^{19}$ The optical absorbance spectra were analyzed for the ratio of OD280 to OD500 (2.0-2.2) and OD360 to OD500 (0.3-0.35), demonstrating that incorporation into the chromophore binding site was at least $90 \%$ and that less than $10 \%$ of nonchromophoric retinal was present. ${ }^{20}$ The absence of nonchromophoric retinal in the sample is confirmed by solid-state NMR (see below). The samples were centrifuged into 4-mm zirconia MAS rotors and stored at $-80^{\circ} \mathrm{C}$. Each full rotor contained approximately $20 \mathrm{mg}$ of labeled protein and $20 \mathrm{mg}$ of lipid, i.e., about $0.45 \mu \mathrm{mol}$ of doubly labeled retinylidene rhodopsin per sample. In some cases, a small disk of $\mathrm{PbNO}_{3}$ was included in the rotor, separated from the protein by Teflon tape for the purpose of temperature calibration. All sample handling was done under dim red light.

2.2. NMR Experiments. The magic-angle spinning NMR experiments were carried out at a spinning frequency of $5500 \mathrm{~Hz}$, in a magnetic field of 9.4 $\mathrm{T}$ on a Varian Infinity+ instrument. The magicangle spinning drive gas was $\mathrm{N}_{2}$, generated by a dedicated liquid $\mathrm{N}_{2}$ evaporation facility. The DQ experiments were performed as described

(16) Birge, R. R.; Knox, B. E. Proc. Natl. Acad. Sci. U.S.A. 2003, 100, 91059107

(17) Yan, E. C. Y.; Kazmi, M. A.; Ganim, Z.; Hou, J.-M.; Pan, D.; Chang, B. S. W.; Sakmar, T. P.; Mathies, R. A. Proc. Natl. Acad. Sci. U.S.A. 2003 , $100,9262-9267$

(18) Groesbeek, M.; Lugtenburg, J. J. Photochem. Photobiol. 1992, 56, 903908

(19) deGrip, W. J.; Daemen, F. J. M.; Bonting, S. L. Methods Enzymol. 1980, 67, 301-320.

(20) de Lange, F.; Bovee-Geurts, P. H. M.; Van Oostrum, J.; Daniël Portier, M.; Verdegem, P. J. E.; Lugtenburg, J.; deGrip, W. J. Biochemistry 1998, $37,1411-1420$

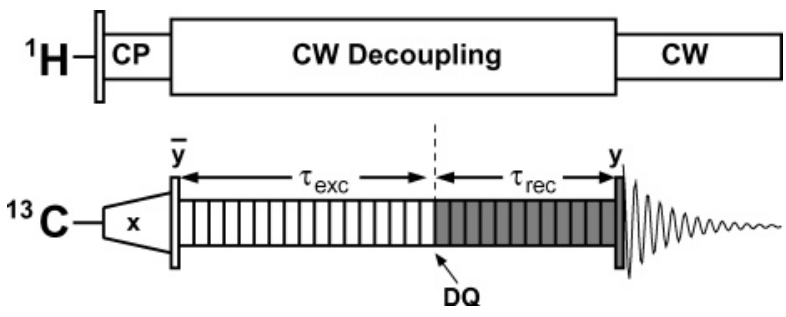

Figure 1. Pulse sequence for excitation of DQ coherences and for ${ }^{13} \mathrm{C}-$ ${ }^{13} \mathrm{C}$ bond length measurement. Enhanced longitudinal ${ }^{13} \mathrm{C}$ magnetization is converted into DQ coherence using the R $14_{2}^{6}$ sequence during the DQ excitation interval, $\tau_{\text {exc }}$. DQ coherence is converted into observable signal by DQ reconversion interval, $\tau_{\text {rec }}$, and a read pulse (shaded block). Continuous-wave decoupling is applied during the recoupling interval and acquisition. The shaded pulse sequence elements are phase cycled to suppress signals not passing through ${ }^{13} \mathrm{C}_{2}$ DQ coherence.

in ref 21 using a DQ recoupling sequence with symmetry $\mathrm{R} 14_{2}^{6}$ and basic element $90_{0} 270_{180} .^{22}$ The relevant pulse sequence is shown in Figure 1. The pulse sequence started with ramped cross-polarization ${ }^{23}$ from the ${ }^{1} \mathrm{H}$ spins to the ${ }^{13} \mathrm{C}$ spins, followed by a $(\pi / 2)_{\bar{y}}$ pulse on the ${ }^{13} \mathrm{C}$ spins to generate enhanced $z$-magnetization. An $\mathrm{R} 14_{2}^{6}$ sequence ${ }^{22}$ of duration $\tau_{\text {exc }}$ converted the longitudinal magnetization into DQ coherence, then reconverted it back into longitudinal magnetization by a second $\mathrm{R} 14_{2}^{6}$ sequence of duration $\tau_{\text {rec. }}$. The NMR signal was observed after a $\pi / 2$ read pulse. The reconversion block and read pulse were subject to phase cycling ${ }^{24}$ to select NMR signals passing through DQ coherence. DQ-filtering removed the natural abundance ${ }^{13} \mathrm{C}$ background signal (Figure 2).

The DQ trajectories shown in Figure 3 were traced by incrementing the DQ excitation interval $\tau_{\text {exc }}$ while keeping the DQ reconversion interval $\tau_{\text {rec }}$ fixed. In all cases, the true sample temperature was maintained at $173 \pm 5 \mathrm{~K}$ during the entire experiment as monitored by measurements of the ${ }^{207} \mathrm{~Pb}$ isotropic chemical shift of $\mathrm{PbNO}_{3}{ }^{25}$ The nutation frequency of the ${ }^{1} \mathrm{H}$ decoupler field was set to $100 \mathrm{kHz}$ during the recoupling sequence and to $80 \mathrm{kHz}$ during signal acquisition. The delay between transients was $5 \mathrm{~s}$. The nutation frequency on the ${ }^{13} \mathrm{C}$ channel during the recoupling sequence was set to $38.5 \mathrm{kHz}$.

Each NMR experiment was first set up on four polycrystalline samples of ${ }^{13} \mathrm{C}_{2}$-labeled all-E-retinal, for which an accurate $\mathrm{X}$-ray structure is available. ${ }^{26}$ These experiments were also used to calibrate the vibrational distance corrections (see below). The experiments were performed on the protein samples under the same conditions as for the model compounds. The DQ reconversion interval was fixed at the following values: $468 \mu$ s for $\left[10,11-{ }^{13} \mathrm{C}_{2}\right],\left[12,13-{ }^{13} \mathrm{C}_{2}\right],\left[14,15-{ }^{13} \mathrm{C}_{2}\right]-$ rhodopsin, $364 \mu \mathrm{s}$ for $\left[11,12-{ }^{13} \mathrm{C}_{2}\right]$-rhodopsin, and $416 \mu$ s for $[13,14-$ ${ }^{13} \mathrm{C}_{2}$ ]-rhodopsin. All radio frequency power levels were calibrated on the model ${ }^{13} \mathrm{C}_{2}$-labeled retinals under identical conditions. We expected the rf power levels in the frozen rhodopsin samples at $173 \mathrm{~K}$ to be very similar to those in the polycrystalline retinals at the same temperature, since the ion motion in the biological samples was effectively quenched. We have verified that sample heating by the $\mathrm{rf}$ field becomes negligible at low temperature. A 3\% uncertainty in the rf field value was included in the data analysis (see below).

Each point in the rhodopsin DQ signal trajectory corresponded to the acquisition of at least 5000 transients. A full experiment trajectory

(21) Carravetta, M.; Edén, M.; Johannessen, O. G.; Luthman, H.; Verdegem, P. J. E.; Lugtenburg, J.; Sebald, A.; Levitt, M. H. J. Am. Chem. Soc. 2001, 123, 10628-10638.

(22) Levitt, M. H. Symmetry-Based Pulse Sequences in Magic-Angle Spinning Solid-State NMR; In Encyclopedia of Nuclear Magnetic Resonance: Supplementary Volume; Grant, D. M., Harris, R. K., Eds.; Wiley: Chichester, UK, 2002; pp 165-196.

(23) Metz, G.; Wu, X.; Smith, S. O. J. Magn. Reson., Ser. A 1994, 110, 219227.

(24) Ernst, R. R.; Bodenhausen, G.; Wokaun, A. Principles of Nuclear Magnetic Resonance in One and Two Dimensions; Clarendon Press: Oxford 1988.

(25) Bielecki, A.; Burum, D. P. J. Magn. Reson., Ser. A 1995, 116, 215-220.

(26) Hamanaka, T.; Mitsui, T.; Ashida, T.; Kakudo, M. Acta Crystallogr. 1972, B28, 214-222. 


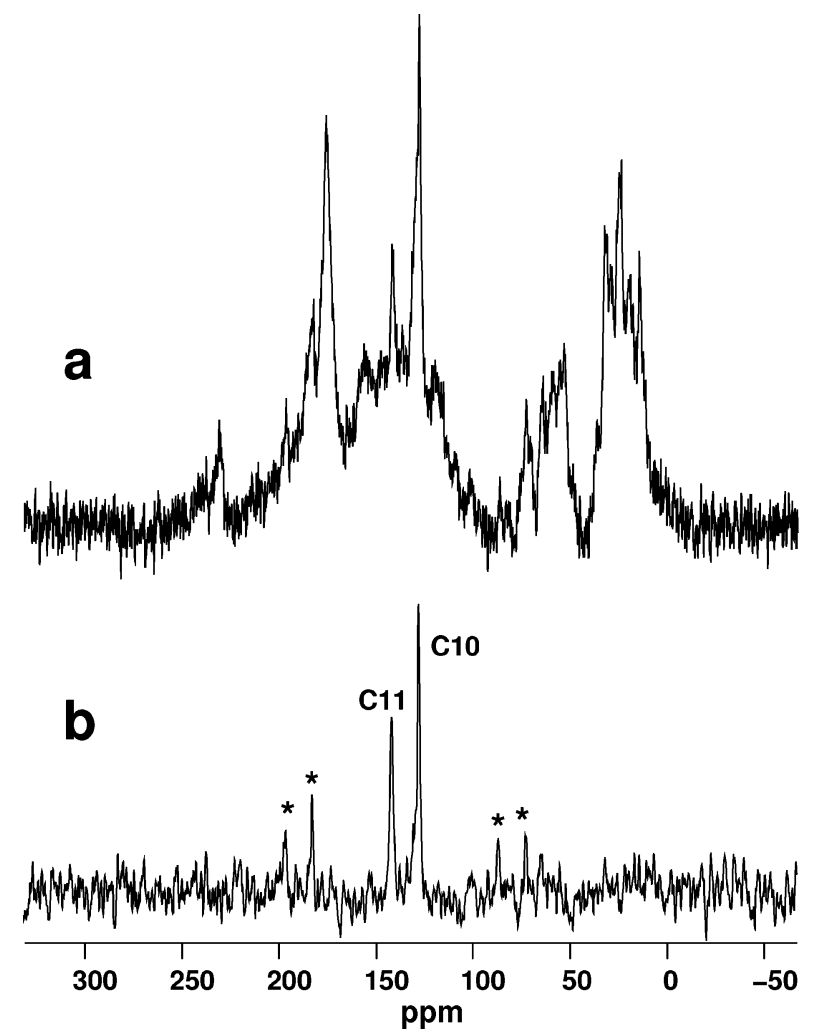

Figure 2. (a) ${ }^{13} \mathrm{C}$ magic-angle-spinning NMR spectrum of $\left[10,11-{ }^{13} \mathrm{C}_{2}\right]-$ retinylidene rhodopsin, acquired using cross-polarization from ${ }^{1} \mathrm{H}$ at a temperature of $173 \mathrm{~K}$. The spectrum is the sum of 1408 acquisitions. (b) DQ-filtered NMR spectrum of $\left[10,11-{ }^{13} \mathrm{C}_{2}\right]$-retinylidene rhodopsin acquired under the same conditions to (a). The spectrum is the sum of 5120 acquisitions. The isotropic signals from the $\mathrm{C} 10$ and $\mathrm{C} 11$ are marked. Spinning sidebands are indicated by asterisks.

lasted about $60 \mathrm{~h}$ on each rhodopsin sample. In the DQ filtered spectra, only peaks due to the labeled chromophore were visible, with no indication of free labeled retinal in the sample.

2.3. NMR Data Analysis. The DQ-filtered signal trajectories were used to estimate the through-space dipole-dipole coupling between the neighboring ${ }^{13} \mathrm{C}$ nuclei. If vibrational effects were neglected, the dipole-dipole coupling was proportional to the inverse cube of the internuclear distance. In practice, the correspondence between internuclear distances measured by XRD and NMR was perturbed by the influence of nuclear motion, which tended to reduce the observed dipole-dipole couplings. This vibrational correction is discussed further below.

The signal amplitude at each point on the signal trajectory was estimated by integrating the DQ-filtered spectrum multiplied by a masking function matched to the signals of interest. The noise level was estimated by repeating the masked integration on many signalfree spectral regions and then performing a statistical analysis to obtain the standard deviation. Spin dynamics simulations were performed using home-built code, incorporating the chemical shift tensors of the coupled sites. Estimation of the carbon-carbon dipolar couplings incorporated the principal values of the chemical shift anisotropies, as obtained from 2D phase-alternated spinning sideband (PASS) ${ }^{27}$ experiments performed at $16.7 \mathrm{~T}$ (S.K., unpublished results). The dipole-dipole couplings and their standard deviations were estimated by numerical spin simulations of the signal points ${ }^{21}$ and their standard deviations, including complete uncertainty in the orientations of the chemical shift anisotropy tensors and a $3 \%$ uncertainty in the value of the rf field experienced by the protein sample, which takes into account rf field inhomogeneity and

(27) Antzutkin, O. N.; Lee, Y. K.; Levitt, M. H. J. Magn. Reson. 1998, 135, $144-155$.

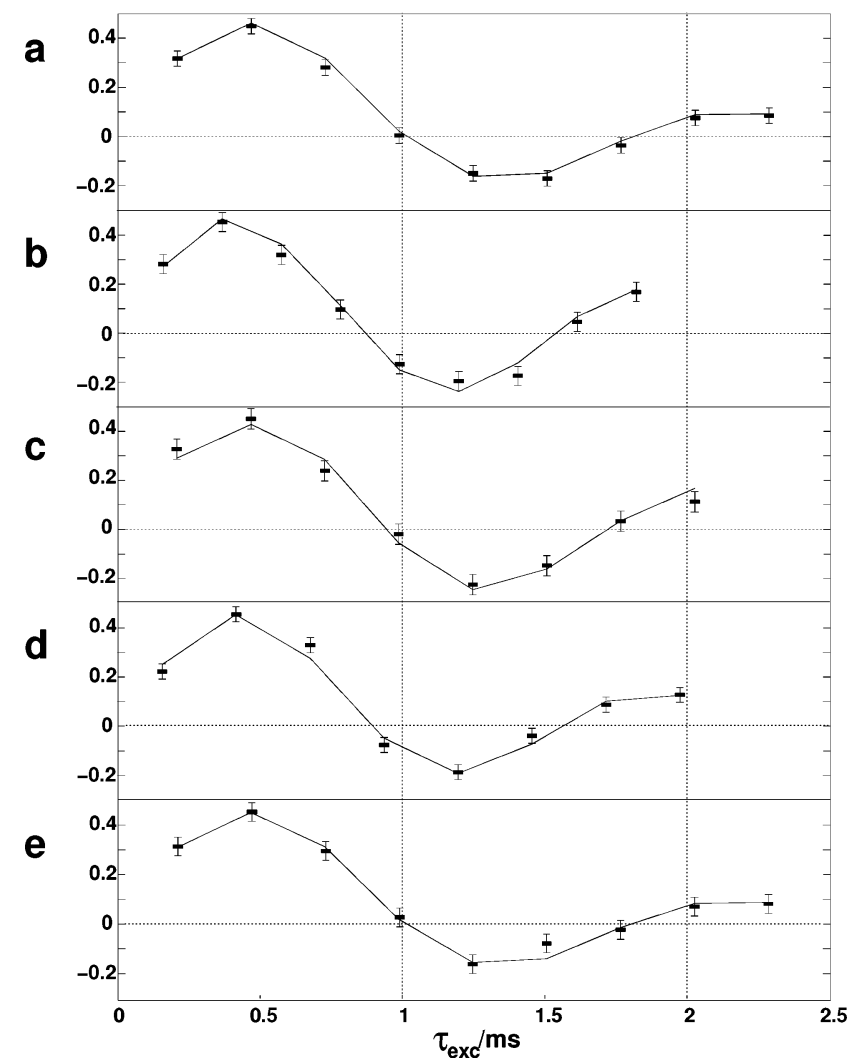

Figure 3. DQ-filtered signal trajectories for ${ }^{13} \mathrm{C}_{2}$-retinylidene rhodopsins, labeled at the following positions: (a) $\left[10,11-{ }^{13} \mathrm{C}_{2}\right]$, (b) $\left[11,12-{ }^{13} \mathrm{C}_{2}\right]$, (c) $\left[12,13-{ }^{13} \mathrm{C}_{2}\right]$, (d) $\left[13,14-{ }^{13} \mathrm{C}_{2}\right]$, and (e) $\left[14,15-{ }^{13} \mathrm{C}_{2}\right]$. The horizontal axis corresponds to the DQ excitation interval in the recoupling pulse sequence. The vertical axis is the DQ signal amplitude (arbitrary units). The solid lines are best-fit numerical simulations corresponding to the distances at the centers of the confidence limits in Table 1.

Table 1. ${ }^{a}$

\begin{tabular}{cccccc}
\hline & \multicolumn{2}{c}{ rhodopsin } & & \multicolumn{2}{c}{ PSB crystals } \\
\cline { 2 - 3 } \cline { 5 - 6 }${ }^{13} \mathrm{C}_{2}$ pair & $r_{\mathrm{NMR}} / \mathrm{pm}$ & $r_{\mathrm{NMR}}^{\text {corr }} / \mathrm{pm}$ & & $r_{\mathrm{XRD}}^{\mathrm{I}} / \mathrm{pm}$ & $r_{\mathrm{XRD}}^{\prime \prime} / \mathrm{pm}$ \\
\hline 10,11 & $146.9 \pm 2.1$ & $143.9 \pm 2.5$ & & $145.7 \pm 0.7$ & $143.1 \pm 1.2$ \\
11,12 & $139.3 \pm 2.0$ & $136.3 \pm 2.4$ & & $132.6 \pm 0.7$ & $132.0 \pm 1.2$ \\
12,13 & $144.0 \pm 2.3$ & $141.0 \pm 2.7$ & & $143.5 \pm 0.7$ & $142.6 \pm 1.2$ \\
13,14 & $139.8 \pm 1.9$ & $136.8 \pm 2.4$ & & $134.6 \pm 0.7$ & $135.1 \pm 1.2$ \\
14,15 & $145.8 \pm 2.2$ & $142.8 \pm 2.6$ & & $140.2 \pm 0.7$ & $139.8 \pm 1.2$ \\
\hline
\end{tabular}

${ }^{a}$ Columns two and three: bond length estimations from the DQ solidstate NMR of [2-retinylidene]-rhodopsin at $173 \mathrm{~K}$ before $\left(r_{\mathrm{NMR}}\right)$ and after $\left(r_{\mathrm{NMR}}^{\text {corr }}\right)$ vibrational correction by $-3.0 \pm 1.3 \mathrm{pm}$. Columns four and five: bond lengths determined by X-ray diffraction on model all-E-PSB crystals, $N$-tert-butyl-retinylideniminium perchlorate $\left(\mathrm{PSB}^{\mathrm{I}}\right)$ and triflate $\left(\mathrm{PSB}^{\mathrm{II}}\right){ }^{30}$ The last three columns in the table are also shown graphically in Figure 4. The confidence limits on the bond lengths are explained in the text.

probe-tuning variations. The experimental data were fitted by multiplying the simulated curves by a biexponential decay function. Optimization of the decay function improved the quality of the fits but had little effect on the determined dipole-dipole couplings. The estimated dipole-dipole couplings $b$ were converted into internuclear distances by inverting the formula $b=-\left(\mu_{0} / 4 \pi\right) \gamma^{2} \hbar r_{\mathrm{NMR}}^{-3}$, where $\mu_{0}$ is the vacuum permeability and $\gamma$ is the gyromagnetic ratio for ${ }^{13} \mathrm{C}$. The estimated bond lengths for the rhodopsin chromophore and their confidence limits are given in column 2 of Table 1 and in Figure 4.

The calibration data on ${ }^{13} \mathrm{C}_{2}$-labeled retinals, shown in the second column of Table 2, when combined with the body of results in ref 21, show that the internuclear distance estimates from XRD and solidstate NMR conform to the relationship $r_{\mathrm{XRD}}=r_{\mathrm{NMR}}-(3.0 \pm 1.3)$ $\mathrm{pm}$. The systematic discrepancy is attributed to the partial averaging of the dipole-dipole interactions by librational motion of the atoms 
Table 2. ${ }^{a}$

\begin{tabular}{cccc}
\hline${ }^{13} \mathrm{C}_{2}$ pair & $r_{\mathrm{NMR}} / \mathrm{pm}$ & $r_{\mathrm{NMR}}^{\text {corr }} / \mathrm{pm}$ & $r_{\mathrm{XRO}} / \mathrm{pm}$ \\
\hline 10,11 & $146.9 \pm 1.1$ & $143.9 \pm 1.7$ & $144.2 \pm 0.5$ \\
11,12 & $138.3 \pm 1.6$ & $135.4 \pm 2.1$ & $133.8 \pm 0.5$ \\
13,14 & $139.3 \pm 1.9$ & $136.3 \pm 2.3$ & $134.4 \pm 0.5$ \\
14,15 & $149.1 \pm 1.9$ & $146.1 \pm 2.3$ & $145.5 \pm 0.6$ \\
\hline
\end{tabular}

a Columns two and three contain bond length estimations in polycrystalline 2-labeled all- $E$-retinals from DQ solid-state NMR at $173 \mathrm{~K}, r_{\mathrm{NMR}}$, and after vibrational correction, $r_{\mathrm{NMR}}^{\mathrm{corr}}$. Column four shows the internuclear distance from X-ray diffraction of all- $E$-retinal, $r_{\mathrm{XRD}}{ }^{26}$ These results show the good agreement between solid-state NMR and high-resolution XRD data. The confidence limits on the bond lengths are explained in the text.

perpendicular to the internuclear vector. ${ }^{21,28}$ In the case of glycine, this effect has been studied by molecular dynamics simulations, ${ }^{28}$ and the predicted discrepancy is in agreement with our data. ${ }^{21}$ According to ref 28 , the temperature dependence of the vibrational correction is expected to be only around $0.5 \mathrm{pm}$ over the temperature range considered in this work and has been ignored. To facilitate comparison with XRD data, we therefore report "vibrationally corrected NMR bond lengths" given by $r_{\mathrm{NMR}}^{\text {corr }}=r_{\mathrm{NMR}}-(3.0 \pm 1.3) \mathrm{pm}$ in Tables 1 and 2 . This assumes that the crystalline retinals and the rhodopsin chromophore have comparable vibrational motion at $173 \mathrm{~K}$. The reported confidence limits in $r_{\mathrm{NMR}}^{\text {corr }}$ include the uncertainty in the vibrational corrections. Since the uncertainties in the NMR distance determination and the vibrational correction are uncorrelated, the confidence limits on $r_{\mathrm{NMR}}^{\text {corr }}$ are calculated as the square root of the summed variances.

The bond length data may be analyzed to obtain the bond length alternation (BLA), $\Delta_{j}$, defined here as the difference between the bond lengths of the two $\mathrm{C}-\mathrm{C}$ bonds along the retinylidene chain on either side of the $j$ th atom:

$$
\Delta_{j}=\left|r_{j-1, j}-r_{j, j+1}\right|
$$

The confidence limits in the NMR estimates of $\Delta_{j}$ are given by summing the variances in the two $r_{\mathrm{NMR}}$ values before vibrational correction and taking the square root. This procedure assumes uncorrelated uncertainties in the two bond lengths. In contrast to the absolute bond lengths, the reported values for the BLA involve no assumption that the vibrational correction is the same for rhodopsin as for the crystalline retinals.

2.4. Interpretation of $X$-ray Data. To compare our NMR data with XRD results on crystalline retinals, we have assessed the confidence limits on bond lengths and BLA values on the basis of the published coordinates and their error margins. The confidence limits were estimated by assuming that the standard deviations of each atomic position were approximately isotropic in Cartesian coordinates and that the positional uncertainties were uncorrelated for different atoms. If the standard deviation for each Cartesian coordinate is denoted $\delta$, it may be shown that the confidence limits in each internuclear distance are $\pm \sqrt{2} \delta$, while the confidence limits in the BLA value are $\pm(4-$ $2 \cos \theta)^{1 / 2} \delta$, where $\theta$ is the bond angle. In the current case, the bond angles are close to $120^{\circ}$; therefore the BLA confidence limits are $\pm \sqrt{5} \delta$. These XRD error margins are shown in Tables $1-3$ and in Figure 5 .

The $2.6 \AA$ structure by Okada et al. ${ }^{10}$ does not have sufficient resolution to define the length of individual $\mathrm{CC}$ bonds.

\section{Results}

The ${ }^{13} \mathrm{C}$ magic-angle-spinning NMR spectrum of $\left[10,11-{ }^{13} \mathrm{C}_{2^{-}}\right.$ retinylidene]-rhodopsin is shown in Figure 2a. Most of the peaks in this spectrum are generated by the naturally $1.1 \%$ abundant ${ }^{13} \mathrm{C}$ nuclei in the protein and lipid environment. The signals from the introduced ${ }^{13} \mathrm{C}_{2}$ labels may be cleanly separated from

(27) Ishii, Y.; Terao, T.; Hayashi, S. J. Chem. Phys. 1997, 107, 2760-2774.
Table 3. ${ }^{a}$

\begin{tabular}{ccrr}
\hline & \multicolumn{3}{c}{ alternation $\Delta / p^{p m}$} \\
\cline { 2 - 4 }${ }^{13}$ C site & rhodopsin & \multicolumn{1}{c}{$\mathrm{PSB}^{\prime}$} & \multicolumn{1}{c}{$\mathrm{PSB}^{\|}$} \\
\hline 11 & $7.6 \pm 3.5$ & $13.1 \pm 1.2$ & $11.0 \pm 1.9$ \\
12 & $4.6 \pm 3.6$ & $10.9 \pm 1.2$ & $10.6 \pm 1.9$ \\
13 & $4.1 \pm 3.5$ & $8.9 \pm 1.2$ & $7.5 \pm 1.9$ \\
14 & $6.0 \pm 3.4$ & $5.6 \pm 1.2$ & $4.7 \pm 1.9$ \\
\hline
\end{tabular}

${ }^{a}$ Column two: alternation in bond lengths from the DQ solid-state NMR of $\left[{ }^{13} \mathrm{C}_{2}\right.$-retinylidene]-rhodopsin at $173 \mathrm{~K}$. Columns three and four: BLA determined by XRD on model all-E-PSB crystals, ${ }^{30}$ as in Table 1 . The confidence limits on the BLA are explained in the text.
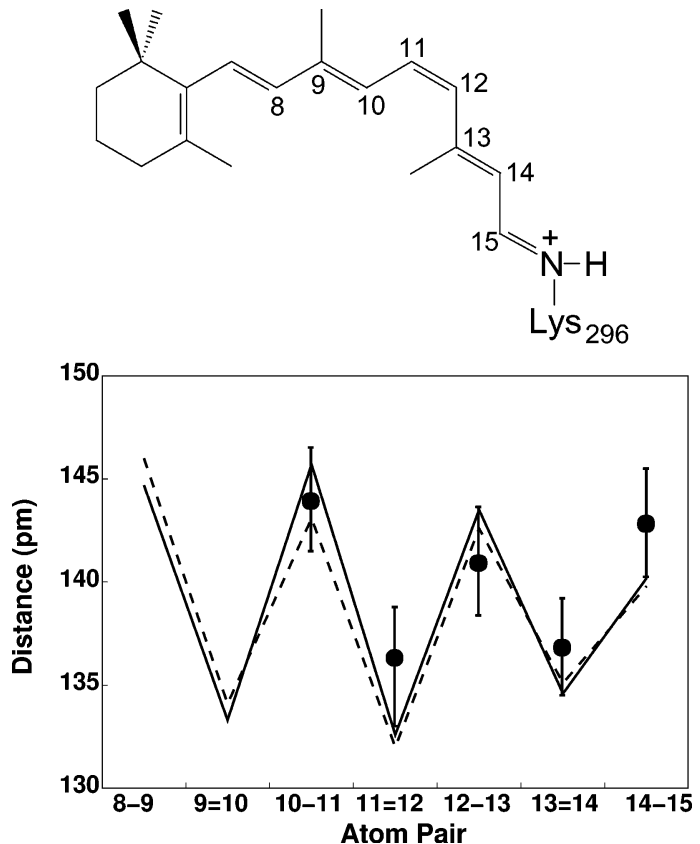

Figure 4. Solid circles: vibrationally corrected NMR bond lengths and confidence limits for the 11-Z-retinylidene chromophore of rhodopsin (see sketch). Solid line: bond lengths in $N$-tert-butyl-all- $E$-retinal perchlorate determined by XRD of crystals. ${ }^{30}$ Dashed line: bond lengths in N-tertbutyl-all- $E$-retinal triflate determined by XRD of crystals. ${ }^{30}$

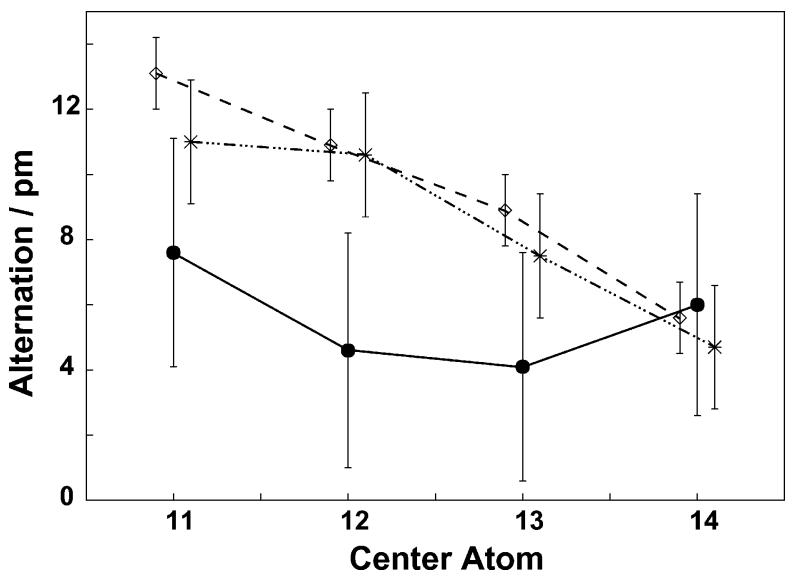

Figure 5. BLA for individual carbon sites and their confidence limits. Solid circles and solid line: $\left[{ }^{13} \mathrm{C}_{2}\right]$-retinylidene rhodopsin determined by solidstate NMR. Empty diamonds and dashed line: BLA for N-tert-butyl-all$E$-retinal perchlorate determined by XRD of crystals. ${ }^{30}$ Stars and dot-dashed line: BLA in $N$-tert-butyl-all-E-retinal triflate determined by XRD of crystals. ${ }^{30}$

the natural abundance background by using symmetry-based recoupling pulse sequences ${ }^{22}$ to excite DQ coherences within the ${ }^{13} \mathrm{C}_{2}$ spin pairs, as illustrated in Figure $2 \mathrm{~b}$ (see Methods 
section). The signals from the pairs of introduced ${ }^{13} \mathrm{C}$ nuclei are clearly evident, together with their spinning sidebands. Similar spectra were obtained for the other ${ }^{13} \mathrm{C}_{2}$-rhodopsin samples.

The magnetic dipole-dipole coupling between the neighboring ${ }^{13} \mathrm{C}$ labels are estimated by varying the pulse sequence intervals. $^{21}$ This procedure generates an oscillating trajectory of the signal amplitudes, as illustrated for the five ${ }^{13} \mathrm{C}_{2}$-labeled rhodopsin samples in Figure 3. Analysis of these trajectories, as described in ref 21 and the Methods section, provides bond length estimates with a spatial resolution of around $3 \mathrm{pm}$. The accuracy of this method was estimated in ref 21. Further calibration results are given in the Methods section. The vibrationally corrected NMR bond lengths estimated on the five $\left[{ }^{13} \mathrm{C}_{2}\right.$-retinylidene]-rhodopsin samples and their confidence limits are summarized in Table 1 and Figure 4.

\section{Discussion}

4.1. Bond Length Alternation. In conjugated chains of alternating double and single bonds, the single bonds typically have a length of around $146 \mathrm{pm}$, while the double bonds have a length of around $133 \mathrm{pm}$. Since the bond order is a measure of the density of $\pi$-electrons between the nuclei, bond lengths have a straightforward relationship with $\pi$-electron density. In particular, a positive charge in a conjugated chain leads to a locally reduced BLA, as known, e.g., from the study of organic conduction in doped polyacetylene chains. ${ }^{29}$

The PSB linkage in rhodopsin carries a positive charge, which is formally located on the nitrogen atom. However, this positive charge readily delocalizes through the conjugated $\pi$-system, and this is reflected in the BLA pattern. Hence, an observed reduction in BLA is a measure of partial positive charge.

For example, consider the high-resolution XRD crystal structures of two all- $E$-retinylidene protonated Schiff bases with aliphatic imine substituents, ${ }^{30}$ as reported in columns 4 and 5 of Tables 1 and 3 and displayed as solid and dashed lines in Figures 4 and 5. Both all-E-PSBs show a strong reduction in BLA toward the end of the chain, revealing the accumulation of positive charge at that position in the conjugated system. Figure $6 \mathrm{a}$ shows a color-coded structure for one of these compounds, $N$-tert-butyl-retinylideniminium perchlorate. Yellow represents bonds which are unperturbed with respect to the typical $133 \mathrm{pm}$ for a conjugated double bond and $146 \mathrm{pm}$ for a typical conjugated single bond. Absolute bond length deviations of $6 \mathrm{pm}$ from these values are indicated in blue, with green indicating intermediate deviations (the deviations are in the positive sense for double bonds and in the negative sense for single bonds). The coloring in Figure 6a emphasizes the strong reduction in BLA at the very end of the chain, next to the PSB linkage. In particular, the $\mathrm{C} 14-\mathrm{C} 15$ single bond is strongly reduced in length to about $140 \mathrm{pm}$ in the PSB crystals. The decay in BLA for the PSB crystal structures is easily visible in Figure 5 .

The measured bond lengths in rhodopsin, determined by solidstate NMR and shown in Table 1 and Figures 4 and 6b, behave quite differently. The data in Figures 4 and 5 show a strong BLA reduction in the vicinity of $\mathrm{C} 12$, while the alternation

(29) Pople, J. A.; Walmsley, S. H. Mol. Phys. 1962, 5, 15-20.

(30) Elia, G. R.; Childs, R. F.; Britten, J. F.; Yang, D. S. C.; Santarsiero, B. D. Can. J. Chem. 1996, 74, 591-601.
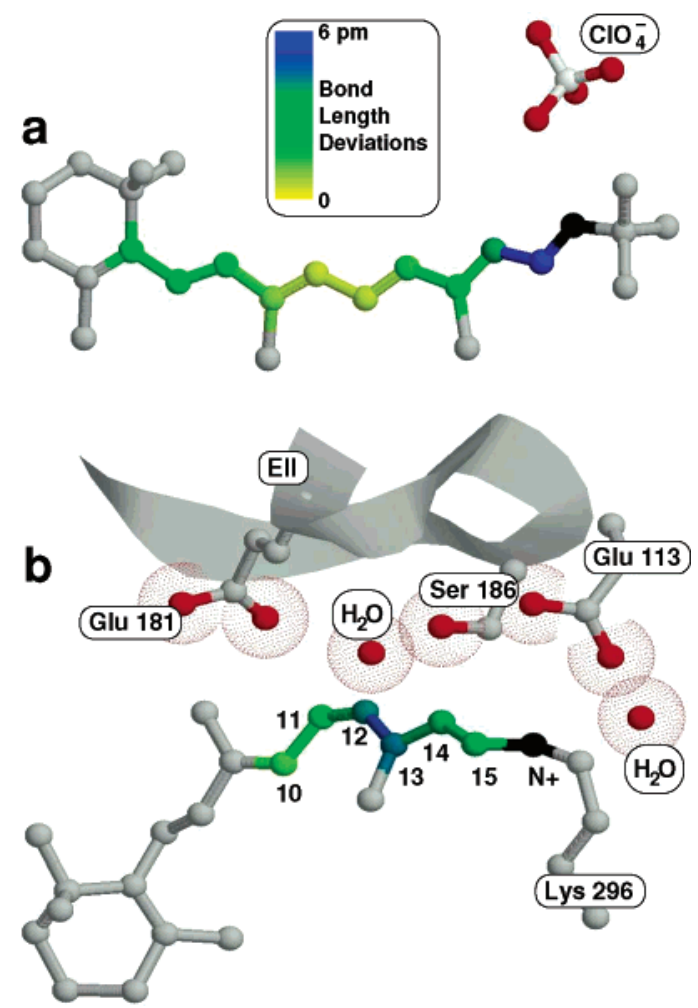

Figure 6. (a) X-ray crystal structure of the retinylidene PSB in N-tertbutyl-retinylideniminium perchlorate, ${ }^{30}$ with the retinal chain color coded, according to the deviation of the high-resolution XRD bond lengths from $133 \mathrm{pm}$ for a conjugated double bond and $146 \mathrm{pm}$ for a conjugated single bond (the deviations are always in the positive sense for the double bonds and in the negative sense for the single bonds). The conjugation defect is located at the PSB end of the chain. (b) $2.6 \AA \mathrm{X}$-ray crystal structure of the environment of the retinylidene PSB chromophore in rhodopsin, from Okada et al., ${ }^{10}$ showing the backbone of the second extracellular loop as a ribbon and the side chains of the neighboring Glu-113, Glu-181, and Ser-186 residues and two water molecules. The $\mathrm{C} 10-\mathrm{C} 11-\mathrm{C} 12-\mathrm{C} 13-\mathrm{C} 14-\mathrm{C} 15$ region of the chromophore is color coded as above, according to the solidstate NMR bond lengths. The plot shows a conjugation defect in the region of $\mathrm{C} 12-\mathrm{C} 13$, close to the structural water molecule between Glu-181 and Ser-186.

recovers at the end of the chain, so that the $\mathrm{C} 14-\mathrm{C} 15$ bond $(142.8 \pm 2.6 \mathrm{pm})$ is much longer than in the PSB crystals.

Although the values of $r_{\mathrm{NMR}}^{\mathrm{corr}}$ in rhodopsin are not significantly different from the crystal structure bond lengths (with the possible exception of the long $\mathrm{C} 14-\mathrm{C} 15$ bond), the determined values of the alternation, $\Delta_{j}$ (eq 1), do show a significant discrepancy between the rhodopsin NMR data and the PSB XRD crystal structure (Figure 5). In part, this is because the bond length perturbations are consistent (single bonds becoming shorter and double bonds becoming longer) and in part because the BLA estimate does not require a vibrational correction. The plot in Figure 5 shows that the BLA is significantly suppressed in the isomerization region of the rhodopsin chromophore. This is emphasized by the fragment of the $2.6 \AA \mathrm{X}$-ray structure of Okada et al. ${ }^{10}$ in Figure $6 \mathrm{~b}$, which shows the retinylidene chromophore in rhodopsin, together with some relevant polar residues near the isomerization point and structural water molecules detected in the latest XRD refinement. ${ }^{10}$ In Figure $6 \mathrm{~b}$, the section in the chain between $\mathrm{C} 10$ and $\mathrm{C} 15$ is color coded to indicate the bond length perturbation determined by solid-state NMR.

4.2. Protein Environment. The salient structural difference between the retinylidene PSB in rhodopsin and the crystalline 
model PSBs is the configuration around the 11,12 double bond. However, a comparison of the XRD structures of all- $E$-retinal ${ }^{26}$ and $11-Z$-retinal ${ }^{31}$ indicates that the cis/trans configuration about the 11,12 bond has only a minor influence on the bond lengths. The striking difference between the BLA in Figure 6a,b must have another origin. It has been postulated that the high photoisomerization efficiency of the rhodopsin chromophore may be due, in part, to the out-of-plane distortion of the molecule due to steric interactions between the hydrogen attached to $\mathrm{C} 10$ and the methyl group attached to $\mathrm{C} 13$. These geometric distortions have been observed both by resonance Raman spectroscopy ${ }^{32,33}$ and solid-state NMR. ${ }^{7}$ However, out-of-plane distortions are more likely to disrupt the conjugation, leading to an increase in BLA in the $\mathrm{C} 10$ to $\mathrm{C} 13$ region. This conflicts with our observations, suggesting that the BLA perturbation is neither purely conformational nor configurational.

The carbon-carbon bond lengths as determined by solidstate NMR indicate a perturbation of the electronic structure of the chromophore and a partial stabilization of the positive charge away from the PSB and near C12. This interpretation is supported by chemical shift data for the retinylidene carbons of bovine rhodopsin $8,34,35$ that are consistent with partial penetration of the PSB positive charge into the retinylidene chain.

The electronic structure of the retinylidene chromophore in rhodopsin has been simulated using density functional theory (DFT). ${ }^{36}$ The calculations were performed using a model for the protein environment based on the $2.8 \AA$ resolution XRD structure by Palczewski et al. ${ }^{9}$ The calculated BLA pattern in the chromophore deviates strongly from the calculated pattern of an isolated retinal PSB. However, these DFT calculations do not predict the relatively long $\mathrm{C} 14-\mathrm{C} 15$ bond and the short C12-C13 bond observed by solid-state NMR. These calculations did not include the structural waters described later by Okada et al. ${ }^{10}$

Hence, the key for understanding the charge perturbation evident in our solid-state NMR data may be the water molecule in the proximity of Glu-181 and Ser- $186^{10}$ that is located about 360-300 pm from C12, C13, and C14. Since extensive dehydration leads to significant spectral shifts, it has been suggested that this water molecule is involved in spectral tuning of the chromophore. ${ }^{9,10}$

There is now considerable evidence that Glu-181 is protonated in the dark state. ${ }^{16,17,37}$ The residues Glu-181, Ser-186, Glu113, and two structural water molecules form a hydrogenbonded network which transfers a proton after photoisomerization of the retinal. ${ }^{16,17}$ This counterion switch is a key element of protein activation at the later stages of the photocycle. The

(31) Gilardi, R. D.; Karle, I. L.; Karle, J. Acta Crystallogr., Sect. B 1972, 28, 2605-2612.

(32) Wang, Q.; Kochendoerfer, G. G.; Schoenlein, R. W.; Verdegem, P. J. E.; Lugtenburg, J.; Mathies, R. A.; Shank, C. V. J. Phys. Chem. 1996, 100 17388-17394.

(33) Palings, I.; Pardoen, J. A.; Van den Berg, E.; Winkel, C.; Lugtenburg, J.; Mathies, R. A. Biochemistry 1987, 26, 2544-2556.

(34) Han, M.; DeDecker, B. S.; Smith, S. O. Biophys, J. 1993, 65, 899-906.

(35) Creemers, A. F. L.; Kiihne, S.; Bovee-Geurts, P. H. M.; deGrip, W. J.; Lugtenburg, J.; de Groot, H. J. M. Proc. Natl. Acad. Sci. U.S.A. 2002, 99 , 9101-9106

(36) Sugihara, M.; Buss, V.; Entel, P.; Elstner, M.; Frauenheim, T. Biochemistry 2002, 41, 15259-15266.

(37) Yan, E. C. Y.; Kazmi, M. A.; De, S.; Chang, B. S. W.; Seibert, C.; Marin, E. P.; Mathies, R. A.; Sakmar, T. P. Biochemistry 2002, 41, 3620-3627. carbon-carbon bond length measurements suggest an additional role for this hydrogen-bonded network: it fixes a water molecule as a bridgehead to solvate and stabilize a local positive charge in the $\mathrm{C} 12-\mathrm{C} 13$ region, assisting the primary photoisomerization process.

4.3. Mechanistic Implications. How can the reduction in BLA around $\mathrm{C} 12$ assist the selective photoisomerization at C11-C12? We propose the following: (1) the isomerization of the $\mathrm{C} 11-\mathrm{C} 12$ double bond involves a transition state with a strongly reduced double bond character of the $\mathrm{C} 11-\mathrm{C} 12$ bond, while the $\mathrm{C} 10-\mathrm{C} 11$ and $\mathrm{C} 12-\mathrm{C} 13$ bonds gain double bond character. ${ }^{38,39}$ The BLA reduction in the $\mathrm{C} 10-\mathrm{C} 11-\mathrm{C} 12-\mathrm{C} 13$ region prepares the nuclear positions along the trajectory for this specific transition state. (2) The torsion in the C10-C11$\mathrm{C} 12-\mathrm{C} 13$ region, observed by solid-state $\mathrm{NMR}^{5,7}$ and resonance Raman spectroscopy, ${ }^{32,33}$ also suggests a preparation of the nuclear positions along the $\mathrm{C} 11-\mathrm{C} 12$ photoisomerization trajectory. (3) Both effects are expected to become even more significant in the electronically and vibrationally excited state, where they will be enhanced by vibrational distortions. ${ }^{1}$ In this context, it should be pointed out that isorhodopsin (which has a $9-Z$ chromophore instead of $11-Z$ ) displays a 3 -fold slower photoisomerization rate than rhodopsin and has a 2.5 -fold smaller quantum yield. ${ }^{1}$ The slower and less efficient photoisomerization of isorhodopsin may be due in part to the much weaker effect of the hydrogen-bonded network on the charge distribution in the $\mathrm{C} 9-\mathrm{C} 10$ region, compared to $\mathrm{C} 11-\mathrm{C} 12$.

To summarize, we postulate that the protein pocket assists the photoisomerization by stabilizing a positively charged conjugation defect in the polyene chain of the chromophore, leading to a local reduction in bond length alternation directly adjacent to the isomerization site. This is accomplished by solvation of the positive charge within the chain through a functional water molecule, positioned and stabilized by a hydrogen-bonded network in the binding pocket, involving two residues of the re-entrant loop EII.

4.4. Methodological Implications. Our results establish an important role of solid-state NMR in structural biology, being able to provide structural details at ultrahigh spatial resolution (a few picometers) even in noncrystalline materials. This is fully complementary to data available from high-resolution crystal structures. We have demonstrated here that the resolution offered by solid-state NMR reveals small local bond length perturbations, exposing specific protein-chromophore interactions of great functional significance. The methodology described here is applicable to a wide range of systems, providing that the relevant biomolecule can be expressed in sufficient quantities and that the ligand can be isotopically labeled.

Acknowledgment. This research was supported by HEFCE and EPSRC (U.K.), by the Göran Gustafsson Association (Sweden), by the Council for Chemical Sciences of The Netherlands Organization for Scientific Research (NWO-CW), and by the Commission of the European Communities (Project BIO4-CT97-2101).

\section{JA039390Q}

(38) Bifone, A.; de Groot, H. J. M.; Buda, F. J. Phys. Chem. B 1997, 101, 2954-2958.

(39) González-Luque, R.; Garavelli, M.; Bernardi, F.; Merchán, M.; Robb, M. A.; Olivucci, M. Proc. Natl. Acad. Sci. U.S.A. 2000, 97, 9379-9384. 